\title{
An Experimental Study of the Lower Flammability Limit of LPG/Halocarbon Mixtures Using the Tubular Burner Apparatus
}

\author{
MURRAY HEIGHT, BOGDAN DLUGOGORSKI and ERIC KENNEDY \\ Process Safety and Environment Protection Research Group \\ Department of Chemical Engineering \\ The University of Newcastle \\ Callaghan, NSW 2308 \\ Australia
}

\begin{abstract}
The motivation for this project is to develop a hydrocarbon-based (ER12) refrigerant that has a lower flammability limit in excess of $5 \%$ refrigerant in air. Optimisation of the hydrocarbon content in the mixture, favourable refrigeration properties, minimal toxicity and benign environmental impact form additional constraints. A variety of compounds were considered as potential flammability reducing additives. The flammability of the various mixtures was evaluated using the tubular flame burner technique. The compounds tested in the initial screening study included $\mathrm{CO}_{2}, \mathrm{CF}_{3} \mathrm{I}, \mathrm{CHF}_{2} \mathrm{Cl}(\mathrm{R} 22), \mathrm{C}_{3} \mathrm{HF}_{7}$ (R227ea), $\mathrm{C}_{3} \mathrm{~F}_{8}$ (R218), $\mathrm{C}_{4} \mathrm{~F}_{10}$ (R3110), $\mathrm{C}_{4} \mathrm{~F}_{8} \mathrm{O}, \mathrm{SF}_{6}, \mathrm{CBr}_{2} \mathrm{~F}_{2}$, 1-bromopropane, 2-bromopropane, $\mathrm{CH}_{2} \mathrm{Br}_{2}$ and $\mathrm{CH}_{2} \mathrm{BrCl}$. Strong flammability reduction performance was observed for $\mathrm{CBr}_{2} \mathrm{~F}_{2}, \mathrm{CH}_{2} \mathrm{Br}_{2}, \mathrm{CF}_{3} \mathrm{I}, \mathrm{C}_{4} \mathrm{~F}_{10}$, $\mathrm{SF}_{6}$ and $\mathrm{C}_{3} \mathrm{~F}_{8}$. Less effective compounds included $\mathrm{CO}_{2}, \mathrm{C}_{3} \mathrm{HF}_{7}$ (R227ea), $\mathrm{CHF}_{2} \mathrm{Cl}$ (R22), $\mathrm{C}_{4} \mathrm{~F}_{8} \mathrm{O}$, and $\mathrm{CH}_{2} \mathrm{BrCl}$. Estimation of potential non-flammable ER12/additive compositions based on the flammability tests revealed the best additives to be $\mathrm{CBr}_{2} \mathrm{~F}_{2}, \mathrm{CH}_{2} \mathrm{Br}_{2}$ and $\mathrm{CH}_{2} \mathrm{Br}_{2}$ each with an ER12 content above 20 mass percent. It is concluded that a practical single additive/ER12 mixture with higher than $20 \%$ ER12 content is unlikely. Compounds containing bromine and iodine possess superior chemical suppression effectiveness with the strength of that effect increasing in proportion to the level of bromination/iodination. Highly fluorinated compounds have excellent suppression efficiency due to the relatively low atomic weight of fluorine. The presence of hydrogen in an additive compound dramatically reduces the suppression efficiency. Inclusion of oxygen and sulphur in compounds can potentially give very good flammability reduction effects. The major environmental and parameters of atmospheric lifetime, ozone depletion potential (ODP) and global warming potential (GWP) were compiled for the screened and targeted additive compounds, with some of the more favourable species shown to possess relatively high atmospheric lifetime and global warming potential despite having zero ozone depleting effect. The toxicological and safety aspects of the compounds are also discussed as an additional means of evaluation of potential additives.
\end{abstract}

KEYWORDS: flammability limits, hydrocarbon refrigerant, tubular burner.

\section{INTRODUCTION}

Since their development in the 1930s, chlorofluorocarbons (CFCs), and in particular dichlorodifluoromethane (R12), have dominated the refrigeration sector due to their high stability, nontoxic and non-flammability characteristics. The extreme stability of CFCs (and Halons), although of great benefit for refrigeration purposes, leads to them remaining in the atmosphere long enough to reach the upper atmosphere where they decompose and ultimately release component halogen atoms $(\mathrm{Cl}, \mathrm{F}, \mathrm{Br})$ into the receiving environment. The halogens of chlorine and bromine in particular, react with atmospheric ozone, thus depleting the atmospheric medium which protects the earth from harmful ultraviolet radiation [1-3]. In September 1987, twenty-six countries (joined by 106 others in 1994) signed the Montreal Protocol, an international treaty to limit and subsequently phase out the production of all significant ozone depleting substances, including CFCs and Halons. The search to find ozone-safe chemical replacements to fill the void created by the implementation of the Protocol has also been complimented by the need to identify compounds that have minimal influence on global warming [4]. Many refrigerant alternatives have been proposed to date, ranging from more environmentally sound hydrochlorofluorocarbons (HCFCs) and other halogenated species, through to 'natural' refrigerants such as ammonia and hydrocarbons [5].

Hydrocarbon compounds, and in particular propane, butane and isobutane, are widely used refrigerants. Hydrocarbons possess zero ozone depletion potential, very low global warming influence, minimal toxicity 
and excellent thermodynamic and lubricant compatibility [5]. The primary concern limiting a more widespread adoption of hydrocarbon refrigerants is their high flammability. The potential of hydrocarbon refrigerants to be high performance alternatives to CFCs has been recognised in a number of studies [6-10]. The hazards associated with the use of hydrocarbon refrigerants have also been reviewed in a number of studies [9, 11-14]. The combination of a chemical fire suppressant with a hydrocarbon refrigerant is an appealing avenue which would ideally reduce the flammability of hydrocarbon mixtures while maintaining favourable thermodynamic characteristics [8]. The search for potential additives that could satisfy this role has formed the central goal of the research described in this paper.

The ideal alternative refrigerant would be a formulation which could be directly added to a refrigeration unit without modification, lubricant recharging or change in refrigeration performance. Such formulations are termed 'drop-in' substitutes, and they are very appealing from a practical perspective. Because the thermodynamic properties of refrigerants are often unique, the likelihood of identifying a single component with identical thermodynamic (pressure-temperature profile) and refrigeration properties is remote. Single component drop-in replacements for R11 and R12 are possible, with the development of R123 and R134a alternatives, however these compounds are often incompatible with the mineral oil lubricants used in the R11 and R12 refrigeration units. Additionally, no single component alternative to R22 or R502 has been identified [3]. The search for drop-in alternatives has broadened to consider mixtures of additives that, in combination, exhibit the required thermodynamic behaviour. Such mixtures can be classed as azeotropes, near-azeotropes and zeotropes. Azeotropic mixtures have identical composition in the liquid and gaseous phases, and so refrigeration performance is not affected by leakage and refrigerant recharging. Azeotropic mixtures are very appealing, however they are rather unusual and somewhat difficult to identify. Previous studies [15] identified a number of the promising binary halocarbon azeotropic mixtures while others examined the performance of halocarbon-hydrocarbon azeotropes [16]. Near zeotropes and zeotropes are mixtures which exhibit changes in composition between the gas and liquid phases. Such formulations exhibit temperature 'glide' in the refrigeration cycle, where the liquid and gas phases exhibit different boiling points due to the variation in composition. Zeotropic mixtures offer more flexibility in terms of tailoring thermodynamic, environmental and flammability properties, however the influence of glide makes them less appealing as drop-in alternatives.

There are two main approaches to reducing the flammability of fuel-air mixtures. The addition of an inert gas uses a physical effect to modify combustion conditions, and the addition of specific suppressant agents affects the combustion via both physical and chemical mechanisms. The addition of an inert gas such as nitrogen or helium to the mixture absorbs a proportion of the heat evolved from the combustion process, thus reducing the energy available to sustain the flame propagation. Carbon dioxide and water act in a similar manner, however these species can have a small chemical influence also.

Chemical suppressants are generally significantly more effective than diluent additives. The efficiency of these compounds is derived from their ability to interfere with combustion chemistry by directly removing flame propagating radicals. Most effective suppressant agents are based on halogenated compounds, with the suppression effect associated with the scavenging of hydrogen radicals by the halogen species to form a halogen acid by-product, effectively removing hydrogen from the flame system and reducing the ability of the flame to propagate [17]. The range of flammable compositions for a fuel/air/additive mixture is bounded by an upper and a lower limit. The upper flammability limit (UFL) is the highest fuel concentration where a mixture will be flammable (for a given fuel, air and additive composition). By contrast, the lower flammability limit (LFL) gives the lowest fuel concentration that will give a flammable mixture.

A potential hazard arising from the use of flammable refrigerants is the scenario where the entire refrigerant charge escapes from the refrigerator unit due to a malfunction or accidental rupture. There would conceivably be a high risk of fire or explosion as the flammable refrigerant mixes with the surrounding air. From a safety perspective, it is therefore essential to have knowledge of the concentration of fuel in the air that is capable of combusting. The lower flammability limit is therefore the parameter of most value for assessing the safety merits of flammable refrigerant mixtures.

The present work aimed to investigate effects of different inerting agents, especially chemical agents, on the lower flammability limit and the inerting concentration of hydrocarbon refrigerants. ER 12, consisting of propane and isobutane, served as an example of a hydrocarbon refrigerant. Especially, in this work we 
determined the minimum concentrations of the inerting agents required to obtained non-flammable mixtures of ER 12. It must be acknowledged that the performance of the gas mixture as a refrigerant is a key parameter which will also need to be assessed if the mixture is to be considered as viable nonflammable refrigerant.

\section{EXPERIMENTAL}

There are a wide variety of experimental techniques available to evaluate the flammability properties of gas mixtures. The older and more established techniques include the Bureau of Mines apparatus [18] and many variations of the explosion sphere. More recent flammability testing methods include the tubular flame burner [19-21] and the opposed flow burner [22]. The techniques used in the current study are the Bureau of Mines apparatus and the tubular flame burner.

\section{Bureau of Mines apparatus}

The Bureau of Mines (BOM) burette apparatus consists of a vertically aligned glass tube. Premixed fuel and air are introduced into the chamber, and the mixture is circulated to achieve a desired concentration. A conventional spark plug positioned midway along the tube is ignited to initiate combustion. If a flame is observed to propagate the full length of the tube (both up and down) then the mixture is deemed flammable. The BOM apparatus is a widely accepted standard for testing flammability of gas mixtures and is a close approximation to the conditions that would be present for explosion of an ambient leak of fuel in air. There are a number of factors which contribute to inaccuracies in the BOM measurements including tube diameter and heat losses to the chamber walls, buoyancy effects and mixture settling gradients and ignition energy variability.

\section{Tubular burner apparatus}

Flammability testing techniques based on special burner configurations have been developed in recent years in an attempt to overcome many of the disadvantages of the Bureau of Mines technique. The burner is based on a tubular sheet of flame which is established within a length of porous tube. A continuous mixture of known composition, consisting of fuel, air and inhibiting agents, is continuously supplied through the porous tube to maintain the flame zone). The flammability limits are determined by incrementally adjusting the feed mixture composition until the flame is extinguished. The composition of the feed mixture at extinguishment is the flammability limit.

The tubular burner has the advantages of rapid analysis time, unambiguous extinguishment condition and excellent reproducibility. Comparison of flammability results obtained from the BOM technique with those found using the tubular burner reveals a tendency for the tubular burner to give wider limits than for the older ignition based techniques. This observation has been widely attributed to lower heat losses from the flame using the burner than for the BOM. Hichens [23] proposed a more satisfactory explanation for this phenomenon which is attributed to preheating of the feed gases giving rise to increased flammability of the gas mixtures with the resultant broadening of the flammability ranges. This preheating effect means the flammability measurement is in effect at a non-standard temperature, however the resulting flammability measurements tend to safer, conservative values because of this influence.

The fundamental difference between the Bureau of Mines technique and the tubular burner method of flammability testing is the initial state of the gas mixture. The BOM technique attempts to ignite a mixture which is initially non-combusted, whereas the tubular burner method attempts to extinguish a continuously combusting gas mixture. The flammability limit of the gas mixture system is therefore approached from opposing directions using each of these techniques. The BOM approaching the limit from a state of nonflammability and the tubular burner from a state of flammability. This duel, complementary approach to finding the limit gives a greater level of confidence in the limit measurements.

The tubular burner relies on a porous tube to evenly distribute the premixed fuel, air and suppressant gas mixture into the combustion zone where a tubular sheet of flame is maintained. The central porous tube is surrounded by a stainless steel manifold to contain and direct the feed mixture. A degree of temperature control for the feed gases is achieved by provision of a cooling coil through which passes a controlled flowrate of water. Two additional lengths of porous tubing above and below the central section issue nitrogen into the extremities of the combustion chamber to extinguish flames and prevent passage of extra air into the combustion region. Two water cooled sections lie outside the nitrogen sections to give 
additional cooling of the burner unit. Fuel, air and additive flowrates are controlled by mass flow controllers, with high range air flowrates (required for lower flammability limits) controlled by a rotameter. A thermocouple was positioned inside the feed gas manifold to gauge the degree of preheating of the gas mixture. An exhaust vent positioned above the burner unit removed any hazardous combustion products from the experiment. A general diagram of the burner configuration is shown in Fig 1.

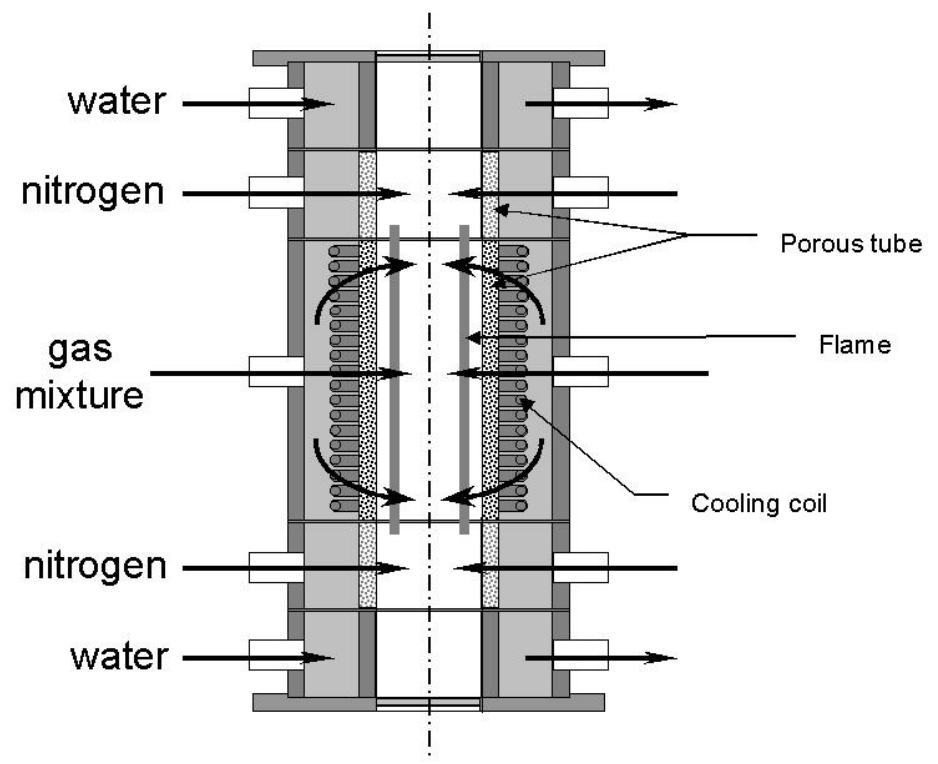

Fig 1. Schematic diagram of tubular burner configuration.

The flammability limits of a mixture refers to the composition of gases that lie on the boundary between mixtures that combust and those that are non-combustible. The term is fundamentally a function of mixture composition. The accurate quantification of gas mixture composition was therefore a primary concern in the operation of both the BOM and tubular burner apparatus. Mixture compositions were determined by calibration of the mass flow controllers, allowing accurate correlation to feed gas compositions. Gas chromatography was also used to directly quantify the composition of gases in the mixtures passing to each of the test equipment. A Shimadzu GC8 gas chromatograph equipped with a thermal conductivity detector was used for gas analysis work in conjunction with quantitative and analysis techniques [24]. A Shimadzu gas chromatograph/mass spectrometer (GCMS) was utilised for identification of chemical species when required.

Operation of the tubular burner involved ignition of the fuel/air gas mixture in the central chamber of the burner before allowing the flame to stabilise and the burner to reach a steady-state temperature and flame character. The flammability limits were determined by incrementally adjusting the composition of the feed mixture, by increasing additive levels or lowering the fuel level (for LFL) until the flame could no longer be sustained. The mixture was formally deemed non-flammable if extinction occurred within one minute of altering the feed composition. The experiments were performed at a constant feed flowrate to reduce the influence of flowfield extinction effects. The Bureau of Mines apparatus was used only sparingly during the experimental program.

\section{RESULTS AND DISCUSSION}

A single of supplier formulated gas mixtures was utilised throughout this project. The LPG hydrocarbon refrigerant mixture marketed as Esanty ER12 served as the base material for all experiments and so it was essential to quantify its composition. The composition of the mixture was determined using gas chromatography, and species identification using a gas chromatograph/mass spectrometer (GCMS). The composition results of ER12 was determined to be $59 \pm 3 \%$ propane $\left(\mathrm{C}_{3} \mathrm{H}_{8}\right), 40 \pm 2 \%$ isobutane $\left(\mathrm{C}_{4} \mathrm{H}_{10}\right)$ and approximately $1 \%$ impurities (primarily nitrogen) by volume. 
We tested a variety of chemical agents to gauge their effectiveness as potential additives. The chemicals tested ranged from gases to liquids and reflected a variety of different chemical structures. The chemicals considered in the project are listed in Table 1.

Table 1. Additive compounds tested during the project.

\begin{tabular}{|l|c|c|}
\hline \multicolumn{1}{|c|}{ Compound name } & Formula & $\begin{array}{c}\text { state @ } \\
\mathbf{2 5 ^ { \circ } \mathbf { C }}\end{array}$ \\
\hline \hline carbon dioxide & $\mathrm{CO}_{2}$ & $\mathrm{G}$ \\
\hline trifluoroiodomethane & $\mathrm{CF}_{3} \mathrm{I}$ & $\mathrm{G}$ \\
\hline chlorodifluoromethane (R22) & $\mathrm{CHF}_{2} \mathrm{Cl}$ & $\mathrm{G}$ \\
\hline 1,1,1,2,3,3,3-heptafluoropropane (R227ea) & $\mathrm{C}_{3} \mathrm{HF}_{7}$ & $\mathrm{G}$ \\
\hline octafluoropropane (R218) & $\mathrm{C}_{3} \mathrm{~F}_{8}$ & $\mathrm{G}$ \\
\hline decafluoropropane (R3110) & $\mathrm{C}_{4} \mathrm{~F}_{10}$ & $\mathrm{G}$ \\
\hline perfluorocyclobutylether & $\mathrm{C}_{4} \mathrm{~F}_{8} \mathrm{O}$ & $\mathrm{G}$ \\
\hline sulfur hexafluoride (R7146) & $\mathrm{SF}_{6}$ & $\mathrm{G}$ \\
\hline dibromodifluoromethane (Halon 1202) & $\mathrm{CBr}_{2} \mathrm{~F}_{2}$ & $\mathrm{G}$ \\
\hline 1-bromopropane (R280B1a) & $\mathrm{C}_{3} \mathrm{H}_{7} \mathrm{Br}$ & $\mathrm{L}$ \\
\hline 2-bromopropane (R280B1) & $\mathrm{C}_{3} \mathrm{H}_{7} \mathrm{Br}$ & $\mathrm{L}$ \\
\hline dibromomethane & $\mathrm{CH}_{2} \mathrm{Br} 2$ & $\mathrm{~L}$ \\
\hline bromochloromethane & $\mathrm{CH}_{2} \mathrm{BrCl}$ & $\mathrm{L}$ \\
\hline bromotrifluoromethane (Halon 1301) & $\mathrm{CF}_{3} \mathrm{Br}$ & $\mathrm{G}$ \\
\hline
\end{tabular}

The lower flammability limit locus for each of these compounds, measured using the tubular flame burner, are presented in Fig 2. The combined plot of the LFL loci for all the compounds ranges from very effective through to very poor performing agents with wide variation between these extremes. Carbon dioxide is included in the above plot as a benchmark to relate the performance of each agent to this neutral compound. The description of the effect that each agent provides is best described by separate discussion of gaseous and liquid compounds.

An immediate observation from the gaseous additive results is that there are three very effective compounds, $\mathrm{CF}_{3} \mathrm{Br}, \mathrm{CF}_{3} \mathrm{I}$ and $\mathrm{C}_{4} \mathrm{~F}_{10}$. Each of these compounds raises the LFL by a large amount with relatively small quantities of additive. Two compounds that are good suppression agents but require higher concentrations to achieve significant effect are $\mathrm{SF}_{6}$ and $\mathrm{C}_{3} \mathrm{~F}_{8}$. Rather poor suppression performance is observed for the compounds $\mathrm{C}_{3} \mathrm{HF}_{7}$ (R227ea) and $\mathrm{CHF}_{2} \mathrm{Cl}$ (R22) with each actually making the ER12 more flammable at low additive concentrations before achieving a suppressant effect at higher additive levels. The compound $\mathrm{C}_{4} \mathrm{~F}_{8} \mathrm{O}$ [25] could not be tested in sufficient quantities to yield much insight into its suppression performance, however the rough trend of the data indicates that it is potentially an effective suppressant agent.

The liquid compounds exhibit a more diverse range of flammability effects than for the gaseous substances. There are two very effective agents, namely dibromodifluoromethane $\left(\mathrm{CF}_{2} \mathrm{Br}_{2}\right.$, Halon 1202) and dibromomethane $\left(\mathrm{CH}_{2} \mathrm{Br}_{2}\right)$ that dramatically increase the LFL with relatively low quantities of additive. This effect is attributed to the presence of two bromine atoms on each of these molecules giving rise to very effective fire suppression efficiency. The result for bromochloromethane $\left(\mathrm{CH}_{2} \mathrm{BrCl}\right)$ shows a lower suppression efficiency with the presence of chlorine giving a more moderate effect than for its dibrominated analogue $\left(\mathrm{CH}_{2} \mathrm{Br}_{2}\right)$. Very poor suppression effectiveness is observed for both bromopropane compounds which resulted in the ER12 becoming more flammable. This is most likely due to the high hydrogenation level of these molecules (7 hydrogen atoms) negating any positive suppression effect of the Bromine. The presence of hydrogen atoms would promote combustion leading to a lowering of the flammability limit. 


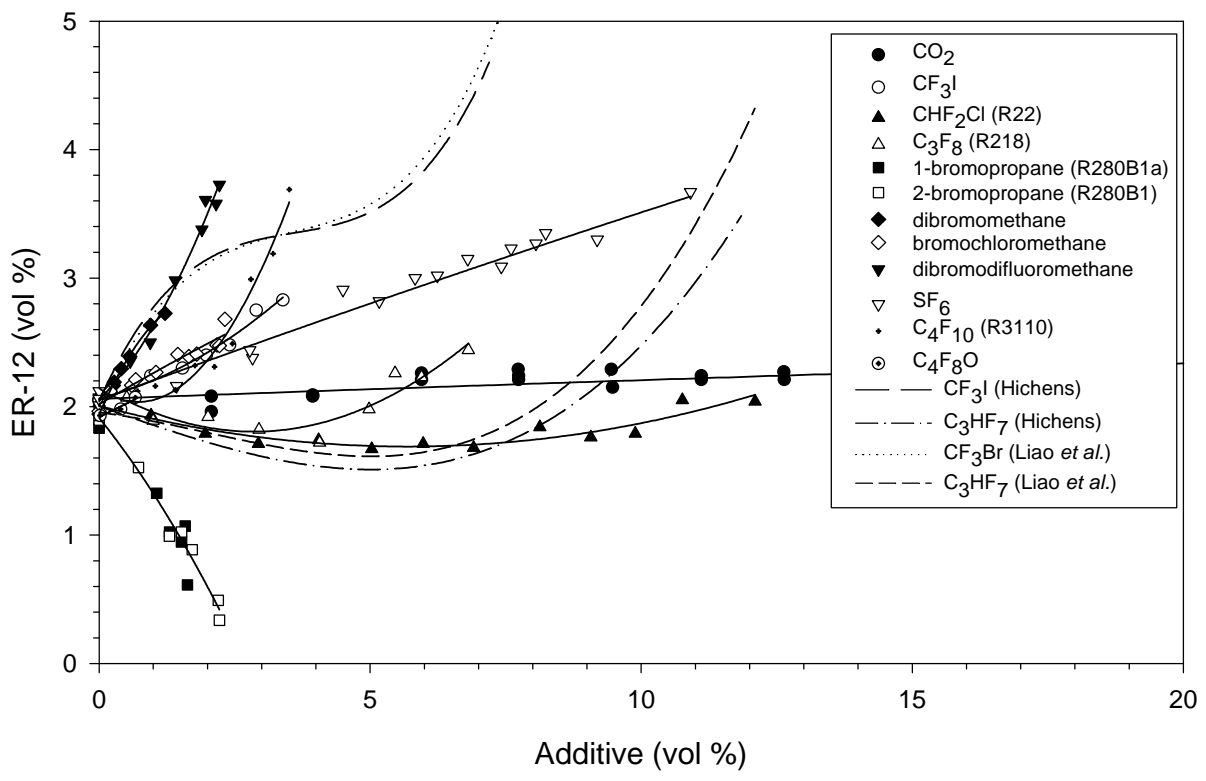

Fig 2. Combined lower flammability limit loci for all additive compounds.

The notion of combining suppressant compounds in a mixture for superior effectiveness than for single components has been proposed [26]. This idea of a synergistic effect when two compounds are combined is interesting and would be a very useful mechanism to explore. Mixtures of $\mathrm{C}_{3} \mathrm{~F}_{8}$ and 2-bromopropane were studied to see if a synergistic effect is possible between a fluorinated and a brominated compound. The flammability results are shown in Fig 3. The flammability loci for the single component additives of 2-bromopropane and $\mathrm{C}_{3} \mathrm{~F}_{8}$ are shown as reference data. The predicted flammability loci for the binary mixtures based on a linear combination of the flammability effect for each component are shown as dashed lines. The measured flammability for $45 \%$ 2-bromopropane lies below the anticipated trend and the $20 \% 2$ bromopropane result is above the predicted value. Although the deviation from the predictions is not very large, the difference does allude to a number of possible phenomena. The effect of introducing more hydrogen to the system (more 2-bromopropane) is not linearly proportional to the additive content, as observed by the larger than expected dip in the 45\% 2-bromopropane result. Similarly the addition of fluorine to the flame (adding more $\mathrm{C}_{3} \mathrm{~F}_{8}$ ) gives a higher than anticipated variation indicating that there is potentially some positive interaction between the bromine and fluorine components.

There is also the possibility that the variation may be due to heat capacity effects rather than a synergistic chemical interaction. There is no striking indication of synergistic effects arising from a binary mixture of this nature, however it seems plausible that a combination of compounds could suppress the flammability via entirely different mechanisms, leading to suppression mechanisms complimenting each other. The potential benefits of such an effect make it worthy of more detailed analysis and investigation. 


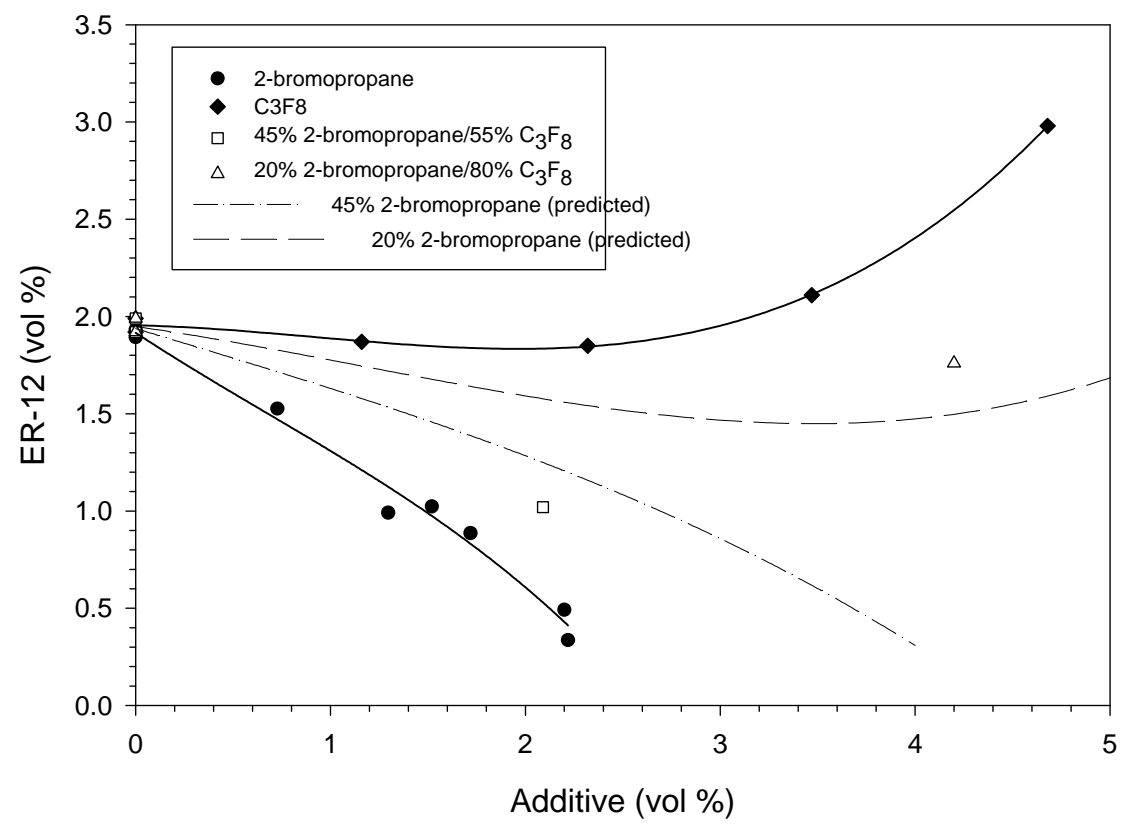

Fig 3. Flammability testing with potentially synergistic suppressant mixtures.

\section{Non-flammable mixtures}

The concentration of suppressant compound that must be added to render the ER12 mixture non-flammable (inert) is a critical parameter for determining the composition of potential mixtures. Elucidation of the inerting composition involves increasing the additive concentration until a non-flammable mixture is achieved. Example plots showing the flammability results up to the inertion point are shown in Fig 4. The ratio of ER12 to additive compound required to form an inflammable refrigerant mixture was estimated for each of the compounds based inertion point measurements and extrapolation of the lower flammability limit loci. The inertion point composition for $\mathrm{SF}_{6}$ is $27 \mathrm{vol} \%$ (11.1 mass\%) ER12 (additive concentration at inertion 13 vol\%; ER12 concentration at inertion 4.8 vol\% means volume ratio of ER12 in ER12/SF6 mixture is $4.8 /(4.8+13)=27 \%$.) while that for R22 is $21.5 \mathrm{vol} \%(13.6$ mass\%). The inertion compositions for each of the additives are shown in Table 2.

The highest ER12 compositions are obtained for the dibrominated liquid additives $\mathrm{CF}_{2} \mathrm{Br}_{2}, \mathrm{CH}_{2} \mathrm{Br}_{2}$ and $\mathrm{CH}_{2} \mathrm{BrCl}$ each with more than 20 mass \% ER12. High ER12 contents are also observed for $\mathrm{CF}_{3} \mathrm{Br}, \mathrm{CF}_{3} \mathrm{I}$, $\mathrm{C}_{4} \mathrm{~F}_{10}$ (R3110), $\mathrm{C}_{3} \mathrm{~F}_{8}$ (R218), $\mathrm{CHF}_{2} \mathrm{Cl}$ (R22), $\mathrm{CHF}_{3}$ (R23) and $\mathrm{SF}_{6}$ (R7146), each having an ER12 content between 10 and 20 mass \%. Less than 10 mass \% ER12 is achieved for $\mathrm{C}_{3} \mathrm{HF}_{7}(\mathrm{R} 227 \mathrm{ea})$ and $\mathrm{CO}_{2}$. The inertion point composition could not be determined for $\mathrm{C}_{4} \mathrm{~F}_{8} \mathrm{O}$ and the flammable species of bromopropane.

The lower flammability limit experiments yielded significant insights into the behaviour of various chemical families. Excellent suppressant efficiency was observed for the brominated and iodinated compounds $\mathrm{CF}_{3} \mathrm{Br}$ and $\mathrm{CF}_{3} \mathrm{I}$, in agreement with previous studies [21,23]. In particular, superior effectiveness was found for the dibrominated compounds $\mathrm{CH}_{2} \mathrm{Br}_{2}$ and $\mathrm{CF}_{2} \mathrm{Br}_{2}$. The performance of the perfluorinated compounds $\mathrm{C}_{3} \mathrm{~F}_{8}, \mathrm{C}_{4} \mathrm{~F}_{10}$ and $\mathrm{SF}_{6}$ was encouraging, particularly for $\mathrm{C}_{4} \mathrm{~F}_{10}$ and $\mathrm{SF}_{6}$. The presence of sulfur in the $\mathrm{SF}_{6}$ molecule displayed some interesting behaviour in comparison with the carbon based analogues. The sulfur based compound gave an immediate and linear increase in flammability limit, wheras the perfluorinated alkanes would show poor effectiveness at low additive concentrations before giving dramatic effectiveness at higher concentrations. 


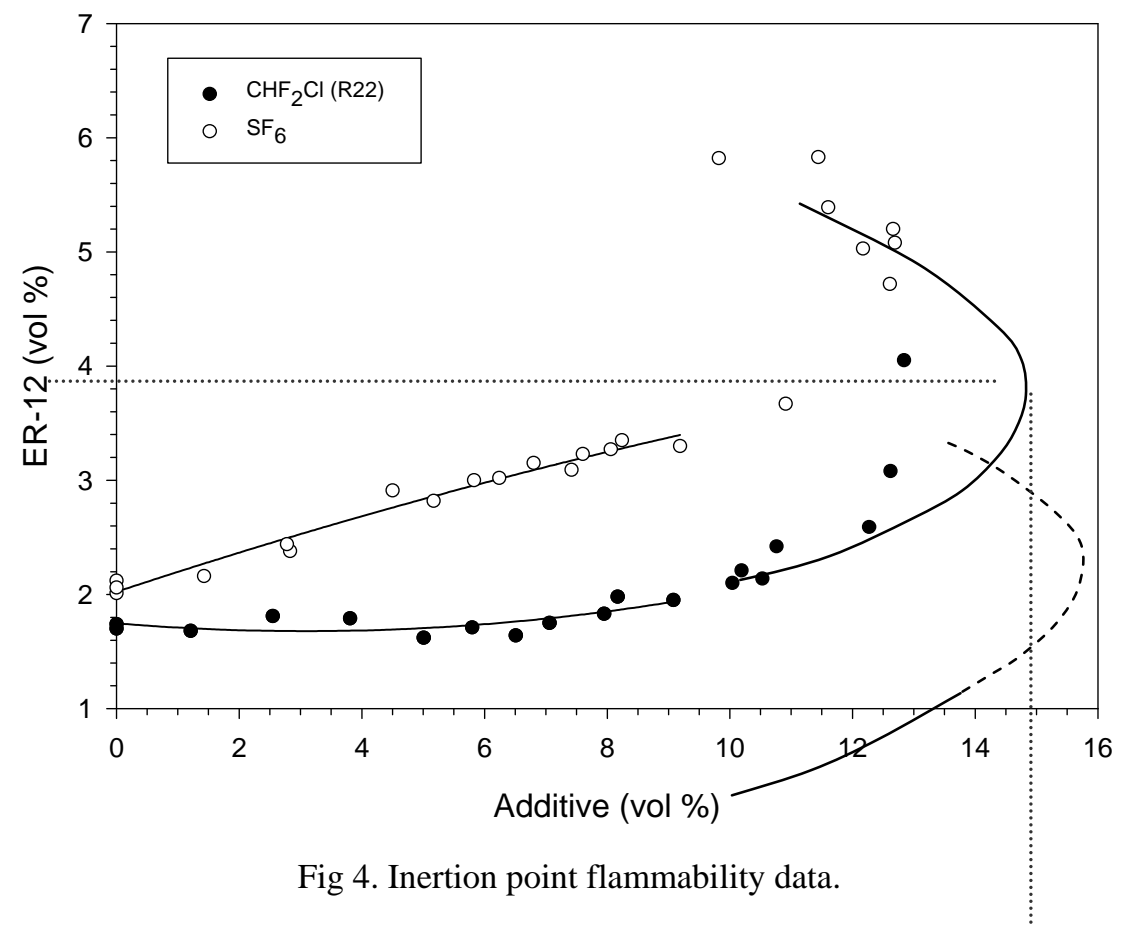

Table 2. Compositions required for non-flammable mixtures, ranked from highest ER12 mass ratio.

\begin{tabular}{|l|c|c|c|c|c|c|}
\hline \multirow{2}{*}{ Additive } & \multicolumn{3}{|c|}{ Volume ratio } & \multicolumn{3}{c|}{ Mass ratio } \\
\cline { 2 - 7 } & Additive \% & ER12 \% & \pm & Additive \% & ER12 \% & \pm \\
\hline dibromodifluoromethane & 35.7 & 64.3 & 13.6 & 70.1 & 29.9 & 10.6 \\
\hline bromochloromethane & 57.1 & 42.9 & 10.6 & 77.7 & 22.3 & 9.6 \\
\hline dibromomethane & 50.0 & 50.0 & 12.5 & 77.8 & 22.2 & 10.2 \\
\hline $\mathrm{CF}_{3} \mathrm{Br}[21]$ & 59.4 & 40.6 & 6.1 & 81.4 & 18.6 & 4.0 \\
\hline $\mathrm{C}_{4} \mathrm{~F}_{10}(\mathrm{R} 3110)$ & 52.9 & 47.1 & 14.9 & 84.4 & 15.6 & 6.7 \\
\hline $\mathrm{CF}_{3} \mathrm{I}[23]$ & 59.8 & 40.2 & 6.4 & 85.5 & 14.5 & 3.2 \\
\hline $\mathrm{CHF}_{2} \mathrm{Cl}(\mathrm{R} 22)$ & 78.5 & 21.5 & 4.2 & 86.4 & 13.6 & 3.8 \\
\hline $\mathrm{CHF}_{3}[21]$ & 83.3 & 16.7 & 3.1 & 87.6 & 12.4 & 3.6 \\
\hline $\mathrm{SF}_{6}(\mathrm{R} 7146)$ & 73.0 & 27.0 & 6.5 & 88.9 & 11.1 & 3.6 \\
\hline $\mathrm{C}_{3} \mathrm{~F}_{8}(\mathrm{R} 218)$ & 69.2 & 30.8 & 10.2 & 89.5 & 10.5 & 4.8 \\
\hline $\mathrm{C}_{3} \mathrm{HF}_{7}$ (R227ea) [21] & 73.8 & 26.2 & 4.9 & 90.6 & 9.4 & 2.2 \\
\hline $\mathrm{CO}_{2}$ & 92.3 & 7.7 & 2.8 & 91.4 & 8.6 & 6.0 \\
\hline $\mathrm{C}_{3} \mathrm{HF}_{7}$ (R227ea) [23] & 77.4 & 22.6 & 4.9 & 92.2 & 7.8 & 1.9 \\
\hline $\mathrm{C}_{4} \mathrm{~F}_{8} \mathrm{O}$ & na & \multicolumn{2}{|c|}{ na } & na & \multicolumn{2}{c|}{ na } \\
\hline 1-bromopropane (R280B1a) & na & \multicolumn{2}{|c|}{ na } & na & \multicolumn{2}{c|}{ na } \\
\hline 2-bromopropane (R280B1) & na & \multicolumn{2}{|c|}{ na } & na & \multicolumn{2}{c}{} \\
\hline
\end{tabular}

The presence of chlorine in the compounds $\mathrm{CH}_{2} \mathrm{BrCl}$ and $\mathrm{CHF}_{2} \mathrm{Cl}$ gave a reduction in suppression performance. Hydrogenated compounds generally showed a tendency to lower the flammability limit and give much weaker suppression action than the halogen saturated analogues. The donation of hydrogen radicals directly from the molecule would tend to promote combustion in competition with the suppressant action of the parent molecule. Highly hydrogenated compounds such as the bromopropane compounds validate this observation with seven attached hydrogen atoms swamping the action of the single bromine atom. 
The slope of the lower flammability limit locus curve can be considered a measure of the suppression effectiveness of different additive compounds. When plotted with the slope (gradient) of the locus against additive concentration, the relative suppression effectiveness of the compounds described in the previous paragraph becomes clear. Compounds that exhibit a positive slope are very effective agents whereas those of negative slope indicate a tendency to lower the LFL and make the mixture more flammable. The locus gradient analysis is plotted in Fig. 5.

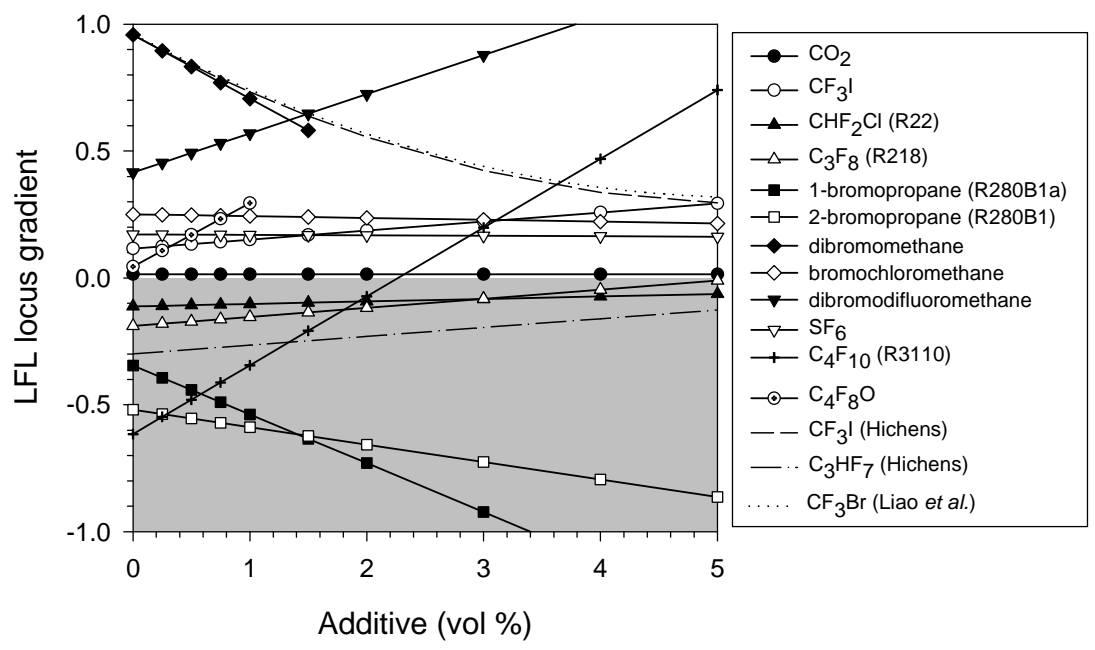

Fig 5. Suppression efficiency comparison.

\section{Potential ER12 based refrigerant mixtures}

A variety of non-flammable refrigerant mixtures are proposed as a result of the flammability study. The refrigerant mixtures are based on ER12 with sufficient single additive component to give the nonflammability inerting composition (Table 2). The proposed compositions are reported in Table 3 in terms of mass ratio. The first three compounds are liquids for temperatures below $20^{\circ} \mathrm{C}$ and so are most likely not suitable for practical refrigeration applications. The Halon compounds $\mathrm{CF}_{3} \mathrm{Br}$ and $\mathrm{CF}_{2} \mathrm{Br}_{2}$ are limited under the Montreal Protocol and are not feasible additives for this reason. The mixtures beginning with $\mathrm{C}_{4} \mathrm{~F}_{10}$ and below in Table 3 are feasible for practical consideration.

Although not thoroughly tested or optimised, there are a number of mixtures with higher combinations of additives that may be more appealing from economic and environmental perspectives. A number of potential mixture combinations are listed in Table 4.

Table 3. Proposed binary compositions of non-flammable ER12 based refrigerant mixtures.

\begin{tabular}{|l|c|c|}
\hline \multicolumn{1}{|c|}{ Additive } & ER12 mass \% & Additive mass \% \\
\hline $\mathrm{CF}_{2} \mathrm{Br}_{2}$ (Halon 1202) & 30 & 70 \\
\hline $\mathrm{CH}_{2} \mathrm{BrCl}$ & 22 & 78 \\
\hline $\mathrm{CH}_{2} \mathrm{Br}{ }_{2}$ & 22 & 78 \\
\hline $\mathrm{CF}_{3} \mathrm{Br}($ Halon 1301) & 18.5 & 81.5 \\
\hline $\mathrm{C}_{4} \mathrm{~F}_{10}(\mathrm{R} 3110)$ & 15.5 & 84.5 \\
\hline $\mathrm{CF}_{3} \mathrm{I}$ & 14.5 & 85.5 \\
\hline $\mathrm{CHF}_{2} \mathrm{Cl}(\mathrm{R} 22)$ & 13.5 & 86.5 \\
\hline $\mathrm{CHF}_{3}(\mathrm{R} 23)$ & 12 & 88 \\
\hline $\mathrm{SF}_{6}(\mathrm{R} 7146)$ & 11 & 89 \\
\hline $\mathrm{C}_{3} \mathrm{~F}_{8}(\mathrm{R} 218)$ & 10.5 & 89.5 \\
\hline $\mathrm{CO}_{2}(\mathrm{R} 744)$ & 8.5 & 91.5 \\
\hline $\mathrm{C}_{3} \mathrm{HF}_{7}(\mathrm{R} 227 \mathrm{ea})$ & 8 & 92 \\
\hline
\end{tabular}


Table 4. Potential additive mixtures to be used with ER12.

\begin{tabular}{|c|c|c|c|}
\hline no. & Additive 1 & Additive 2 & Additive 3 \\
\hline 1 & $\mathrm{CF}_{3} \mathrm{I}$ & $\mathrm{C}_{4} \mathrm{~F}_{10}(\mathrm{R} 3110)$ & - \\
\hline 2 & $\mathrm{CF}_{3} \mathrm{I}$ & $\mathrm{SF}_{6}(\mathrm{R} 7146)$ & - \\
\hline 3 & $\mathrm{CF}_{3} \mathrm{I}$ & $\mathrm{C}_{3} \mathrm{~F}_{8}(\mathrm{R} 218)$ & - \\
\hline 4 & $\mathrm{CF}_{3} \mathrm{I}$ & $\mathrm{CHF}_{2} \mathrm{Cl}(\mathrm{R} 22)$ & - \\
\hline 5 & $\mathrm{CF}_{3} \mathrm{I}$ & $\mathrm{CHF}_{3}(\mathrm{R} 23)$ & - \\
\hline 6 & $\mathrm{CF}_{3} \mathrm{I}$ & $\mathrm{C}_{2} \mathrm{H}_{2} \mathrm{~F}_{4}(\mathrm{R} 134)$ & - \\
\hline 7 & $\mathrm{CF}_{3} \mathrm{I}$ & $\mathrm{C}_{4} \mathrm{~F}_{8} \mathrm{O}$ & - \\
\hline 8 & $\mathrm{C}_{4} \mathrm{~F}_{10}(\mathrm{R} 3110)$ & $\mathrm{CHF}_{2} \mathrm{Cl}(\mathrm{R} 22)$ & - \\
\hline 9 & $\mathrm{C}_{4} \mathrm{~F}_{10}(\mathrm{R} 3110)$ & $\mathrm{CHF}_{3}(\mathrm{R} 23)$ & - \\
\hline 10 & $\mathrm{C}_{4} \mathrm{~F}_{10}(\mathrm{R} 3110)$ & $\mathrm{SF}_{6}(\mathrm{R} 7146)$ & $\mathrm{SF}_{6}(\mathrm{R} 7146)$ \\
\hline 11 & $\mathrm{CF}_{3} \mathrm{I}$ & $\mathrm{C}_{4} \mathrm{~F}_{8} \mathrm{O}$ & \\
\hline
\end{tabular}

The exact composition ratios for these mixture combinations will need to be determined experimentally. The compositions of mixtures 2, 7, 10 and 11 are anticipated to show very good non-flammability performance due to the speculated complimentary fire suppression mechanisms of the component compounds.

\section{Environmental considerations}

The critical environmental parameters that govern the suitability of additive compounds are measures of the atmospheric lifetime, ozone depletion potential (ODP) and global warming potential (GWP). A decision tree for environmental impact screening of CFC replacements has been developed, which considers the anticipated atmospheric lifetime of the substance, ozone depletion potential and finally the global warming potential [27]. In this evaluation process, substances with an excessive atmospheric lifetime, ODP or GWP should be rejected as replacements and a successful compound must exhibit low values for all of these parameters.

The only compounds that have significant ozone depletion potential are those molecules containing bromine or chlorine. The brominated halon compounds show the highest ODPs and would be unsuitable for practical use, which is reflected in their controlled status under the Montreal Protocol [28]. The only compound of some potential as an additive that may be compromised by its ODP is $\mathrm{CHF}_{2} \mathrm{Cl}$ (R22) which is a controlled substance under the Montreal Protocol and will be phased out prior to 2030. The stability of the highly fluorinated compounds is once again evident in the high global warming potential for these additives. The most damaging of the proposed compounds in terms of global warming is $\mathrm{SF}_{6}(23,900)$ followed by $\mathrm{C}_{2} \mathrm{~F}_{6}(9,200), \mathrm{C}_{4} \mathrm{~F}_{8}(8,700), \mathrm{C}_{6} \mathrm{~F}_{14}(7,400), \mathrm{C}_{4} \mathrm{~F}_{10}(7,000), \mathrm{C}_{3} \mathrm{~F}_{8}(7,000), \mathrm{CF}_{4}(6,500), \mathrm{C}_{3} \mathrm{H}_{2} \mathrm{~F}_{6}$ $(6,300)$ and $\mathrm{C}_{3} \mathrm{HF}_{7}(2,900)$. The global warming potential of these compounds can be avoided by adopting an analogous species with less stability in a similar fashion to the approach proposed for reducing the atmospheric lifetime.

Based on the environmental impact potentials, a number of the proposed compounds stand out as appealing additive alternatives. A particularly appealing compound from this perspective is $\mathrm{CF}_{3} \mathrm{I}$ which exhibits very low atmospheric lifetime and GWP and a very small ODP which is mitigated by the low lifetime. The weakness of the iodine bond to carbon within the molecule gives rise to this atmospherically unstable effect. Other attractive additives include $\mathrm{CHF}_{3}$ (R23), $\mathrm{C}_{2} \mathrm{H}_{2} \mathrm{~F}_{4}$ (R134a) and $\mathrm{C}_{3} \mathrm{H}_{3} \mathrm{~F}_{5}$ (R245ca). It is also anticipated that the unsaturated $\mathrm{C}_{2} \mathrm{H}_{2} \mathrm{Br}_{2}$ and the ether based compounds $\mathrm{C}_{4} \mathrm{~F}_{8} \mathrm{O}$ and $\mathrm{C}_{2} \mathrm{~F}_{6} \mathrm{O}$ would show promise as they are likely to possess lower atmospheric lifetimes than their saturated and perfluorinated analogues due to their inherent instability.

\section{Toxicology and safety considerations}

Most of the compounds listed in exhibit some form of acute exposure effect. A typical effect is that of cardiac sensitisation where the heart beat can become irregular through the alteration of the heart's electrical activity. There is generally a progressive series of symptoms ranging in severity from dizziness through to anaesthesia and irritation. The severity and onset of these effects is of course particular to the material. The chronic effects of these compounds have generally not been catalogued in great detail, 
although for most of the additives listed previously there are no major long term effects for prolonged exposure. An exception to this is with the brominated species which exhibit potential to cause damage to the liver, kidney, heart, lung and nervous system. The specific toxicological properties of each compound should be considered in more detail using the relevant material safety data sheets.

The majority of halogenated compounds are non-flammable and it generally requires a compound with a high hydrogenation level to elicit combustibility. Halogenated compounds showing some degree of flammability are $\mathrm{C}_{2} \mathrm{H}_{4} \mathrm{~F}_{2}$ (R152a), $\mathrm{C}_{3} \mathrm{H}_{3} \mathrm{~F}_{5}$ (R245ca) and $\mathrm{CH}_{3} \mathrm{Br}$ (Halon 1001).

\section{CONCLUSIONS}

- The tubular burner apparatus is a very effective tool for studying the flammability limits of hydrocarbon/halocarbon mixtures.

- The addition of relatively small amounts of $\mathrm{CBr}_{2} \mathrm{~F}_{2}, \mathrm{CH}_{2} \mathrm{Br}_{2}, \mathrm{CF}_{3} \mathrm{I}, \mathrm{C}_{4} \mathrm{~F}_{10}, \mathrm{SF}_{6}$ and $\mathrm{C}_{3} \mathrm{~F}_{8}$ can decrease the lower flammability limit of propane/isobutane (LPG) gas.

\section{REFERENCES}

[1] Didion, D.A. (1999) Influence of the thermophysical fluid properties of the new ozone-safe refrigerants on performance. International Journal of Applied Thermodynamics, Vol. 2, No. 1, 1935.

[2] Didion, D.A. (1994) The impact of ozone-safe refrigerants on refrigeration machinery performance and operation, Transaction of Naval Architects and Marine Engineering. 10/1-15.

[3] Didion, D. A., (1994) Role of refrigerant mixtures., Bulletin of International Institute of Refrigeration, No. 94-3, 6-11.

[4] Calm, J.M. and Didion, D.A. (1997) Trade-Offs in Refrigerant Selections: Past, Present, and Future, Refrigerants for the 21st Century, ASHRAE/NIST Refrigerants Conference, National Institute of Standards and Technology. ASHRAE (2002) Ammonia as a refrigerant: Position paper, ASHRAE, Atlanta, Ga.

[5] Aisbett, E. and Q.T. Pham (1998) Natural replacement for ozone-depleting refrigerants in eastern and southern Asia. International Journal of Refrigeration, Vol.21 No.1 p.18-28.

[6] Choi, D. K.; Domanski, P. A.; Didion, D. A. Evaluation of Flammable Refrigerants for Use in a Water-to-Water Residential Heat Pump. International Institute of Refrigeration. Applications for Natural Refrigerants. Proceedings. September 3-6, 1996, Aarhus, Denmark, 467-476

[7] Kim, M.S., Mulroy, W.J. Didion, D.A. (1994) Performance evaluation of two azeotropic refrigerant mixtures of HFC-134a with R-290 (Propane) and R-600a (Isobutane), Transactions of the ASME, Journal of Energy Resources Technology, 116, pp148-154. doi:10.1115/1.2906020

[8] Maclaine-cross, I.L. (1996) Hydrocarbon refrigerant leaks into car passenger compartments, School of Mechanical and Manufacturing Engineering, The University of New South Wales, Sydney.

[9] Payne, W.V., Domanski, P.A. Muller, J. (1998) A study of a water-to-water heat pump using flammable refrigerants, Proceedings Natural Working Fluids '98 IIR-G Lorentzen Conference., Oslo.

[10] Maclaine-cross, I.L. (1993) Hydrocarbon refrigerants and motor car air-conditioning, Green Fridge Quest, School of Mechanical and Manufacturing Engineering, The University of New South Wales, Sydney.

[11] Maclaine-cross, I.L. (1994) FIREBALL: A brief report on pilot experiments to measure the insurance risk of hydrocarbon refrigerants in motor cars, School of Mechanical and Manufacturing Engineering, The University of New South Wales, Sydney. 
[12] Maclaine-cross, I.L., (2004) Usage and risk of hydrocarbon refrigerants in motor cars for Australia and the United States International Journal of Refrigeration 27,(4), 339-345.

[13] UNEP (1996) Safety Aspects of Hydrocarbon Refrigerators, OzonAction Information Clearinghouse, United Nations Environment Programme.

[14] Morrison, G. and McLinden, M. (1993) Azeotropy in Refrigerant Mixtures, International Journal of Refrigeration, 16, 129-138. doi:10.1016/0140-7007(93)90069-K

[15] Kim, M.S., Morrison, G., Mulroy, W.J. Didion, D.A. (1996) NISTIR 5784, A study to determine the existence of an azeotropic R-22 "drop-in" substitute, Building and environment division, Building and fire research laboratory, National Institute of Standards and Testing, Gaithersburg.

[16] Dixon-Lewis, G., Simpson, R.J. (1976) Aspects of flame inhibition by halogen compounds, Sixteenth Symposium (International) on Combustion, The Combustion Institute, pp1111-1119.

[17] Coward, H.F. and Jones, G.W. (1952) Limits of Flammability of Gases and Vapours, US Bureau of Mines Bulletin, Washington DC, 503.

[18] Ishizuka, S. (1991) Determination of Flammability Limits using a Tubular Flame Geometry, Journal of Loss Prevention in the Process Industries, 4.

[19] Saito, N., Saso, Y., Liao, C., Ogawa, Y. Inoue, Y. (1995) Flammability Peak Concentrations of Halon Replacements and Their Function as Fire Suppressants, Halon Replacements, pp243-257.

[20] Liao, C., Saito, N., Saso, Y. Ogawa, Y. (1996) Flammability Limits of Combustible Gases and Vapors Measured by a Tubular Flame Method, Fire Safety Journal, 27, pp49-68. doi:10.1016/S0379-7112(96)00021-5

[21] Womeldorf, C., King, M. Grosshandler, W. (1995) Interim technical report - Phase I, Lean flammability limit as a fundamental refrigerant property, Building and fire research laboratory, National Institute of Standards and Testing, Gaithersburg.

[22] Dlugogorski, B. Z.; Hichens, R. K.; Kennedy, E. M. (2002), Inert hydrocarbon - based refrigerants Fire Safety Journal 37(1), 53-65. doi:10.1016/S0379-7112(01)00023-6

[23] Height, M.J., Kennedy, E.M. Dlugogorski, B.Z. (1999) Thermal conductivity detection relative molar response factors for halogenated compounds, Jounal of Chromatography A, 841, pp187195. doi:10.1016/S0021-9673(99)00365-9

[24] Pruette, L, Karecki, S., Reif, R., Tousignant, L., Reagen, W., Kesari, S. and Zazzera, L. (2000) Evaluation of C4F8O as an Alternative Plasma Enhanced Chemical Vapor Deposition Chamber Clean Chemistry, Journal of the Electrochemical Society 147(3), 1149-1153. doi:10.1149/1.1393328

[25] Tapscott, R.E., Moore, T.A.Lifke, J.L. (1998) WO98/09686, Hydrocarbon blends to protect against fires and explosions, International patent.

[26] Tapscott, R.E., Olivares-Sooley, M.G. (1998) A decision tree for global environmental impact screening, Halon Options Technical Working Conference, (HOTWC), Albuquerque New Mexico, 315-323.

[27] UNEP (1994) Elimination of CFC refrigerants from domestic refrigeration manufacture, OzonAction Information Clearinghouse, United Nations Environment Programme. 